coefficient, and the like, which are not fundamental magnitudes of the type previously discussed, but may none the less be measured quantitatively. Whether the magnitudes concerned are fundamental or not, a mass, a temperature (not a hotness), a viscosity, even though they may be conceived artificially as built up by the multiplication of a certain unit quantity, do surely present themselves to introspection with the same singularity as does, say, a sensation-brightness.

Moreover (we are now in the region of physical stimuli), even though a physical magnitude $X$ may present itself to introspection as a whole, if we find that $X$ varies with temperature in such a way that $d X / d \theta=f(\theta)$, we have no hesitation in integrating to obtain a functional relation between $X$ and $\theta$, and are led thereby into no contradictions. So, while fully recognising that in one instance we are making deductions from introspection concerning a physical magnitude, and in the other instance from our judgment concerning a subjective sensation, we do not find ourselves led into any morass of contradiction if we regard a just noticeable difference or an equal-appearing interval as a unit of sensation, and artificially regard any sensation magnitude as so many times greater than that unit.

This is, apparently, what Dr. Houstoun doesand in doing so ingeniously avoids difficulties arising from departures from Weber's Law - when he plots $R \div(\delta R / \delta S)$ as ordinate against $(\log R)$ as abscissa. Since $d(\log R)$ is equal to $\delta R / R$, it follows that the area included between two ordinates separated by the small interval $d(\log R)$, the $x$-axis, and the element of the curve is equal to $\delta S$. Consequently, if $\Sigma \delta S=S$, the magnitude of the sensation corresponding to any stimulus $R$, is given by the area underneath the curve up to the ordinate at the point considered. This expresses an important advance. Incidentally, Dr. Houstoun finds that the curve obtained is very closely a Gaussian probability curve.

Other minor criticisms may be briefly noted. It has been remarked that the quantity $S-S_{0}$ does not represent a difference between two experiences, but an experience of difference. "The expression $S-S_{0}$ represents a single state of consciousness, the experience of a difference. It admits neither of dissection nor of mathematical treatment." Such a statement is merely dogmatic. Again, criticism of the choice of a just noticeable difference as a unit is contained in the remark that Fechner " regarded a sensation as the sum of a number of just appreciable unit increments of sensation. . . He main- tained that the change of sensation, obtained by adding one ounce to a weight of twenty-nine ounces was absolutely the same as that obtained by adding one dram to a weight of twenty-nine drams. Of course, were this so, an ounce and a dram should produce an equal sensation." The italics are the present writer's. Comment is surely unnecessary.

Dr. L. F. Richardson has approached the matter from a different viewpoint. $\mathrm{He}$ endeavours to measure a sensation $S$ " by directly estimating the ratio of unequal intervals both much larger than the least perceptible". Thus he has, from 316 observers, obtained estimates of the redness of certain pinks, these estimates being made by putting points on a line divided into 100 equal parts, white being zero, and red 100. The inquiry has been elaborated by mixing on a colour-wheel white and red in different proportions and estimating in the same way the redness of the resulting colour. If $X$ is the position of the mark on the red scale and the angular amount of red (measured as a percentage of $360^{\circ}$ ) is $\theta, \mathrm{R}$. S. Maxwell finds that the results of 35 observers may be represented by $(\theta-156)(X+56)=-8736$.

One word concerning the decibel. This may, or may not, be used to define a unit of sensationloudness. The physical measure of the intensity of a musical note of a given pitch rises, apparently, at a much more rapid rate than does the judgment of its sensation-loudness. If we measure physical intensities in, say, micro-watts per square centimetre, we obtain a series of numbers $1,10,100$, $1000 \ldots$ or $10^{0}, 10^{1}, 10^{2}, 10^{3} \ldots$ As a matter of mere convenience it may be advisable to represent these intensities by the series $0,1,2,3 \ldots$, and we thus obtain a logarithmic scale of intensities of which the unit has been called the bel. Onetenth of this unit is the decibel, and it does happen that this unit corresponds fairly closely to the just noticeable difference of sensation-loudness between two notes of the same pitch at moderate intensities. But primarily the decibel represents a unit of intensity on a logarithmic scale, and need have no more to do with sensation measurements than has a scale of cents in the realm of music.

It is evident that, despite the amount of adverse criticism that has been brought to bear on Fechner's interpretation of Weber's Law, the matter is by no means closed, and that even the long-standing evasion of the difficulties in terms of sensationintervals may stand in need of revision. The joint discussion between Sections A and $J$ at the York meeting of the British Association should do much to clear up the major points at issue.

\title{
Obituary
}

\section{MR. H. G. WATKINS}

THE tragic death on Aug. 20 of Henry George Watkins at the age of twenty-five years has removed the most promising and, indeed, the most prominent figure amongst British arctic explorers, a figure as yet too recent to be familiar to those outside a small circle.
The stages of Watkins' rapid advance to the forefront are simply told. At the age of nineteen, while still an undergraduate at Trinity College, Cambridge, he led a summer expedition to Edge Island in the Spitsbergen group. At the age of twenty he spent an arduous year in Labrador with one companion, J. M. Scott, the full story of which 
has not yet been written. At the age of twentythree he led the British Arctic Air Route Expedition of 1930-31 in Greenland, a venture which is destined to be an important milestone along the road of polar history.

The full significance of the Greenland expedition has probably not yet penetrated the mind of the public, which was intrigued by and slightly critical of the dramatic events which surrounded the relief of Courtauld after his five months' sojourn alone on the ice cap. The narrative, now in the hands of a publisher, will correct some of the misapprehensions and will prove to the readers that here was a new type of expedition, following no former pattern : for Watkins ventured greatly without the lead of tradition; indeed, he constantly questioned the value of traditional methods and devised new and original ones of his own.

Led by Watkins, this group of young and inexperienced men set to work to disprove the wise saws of tradition, to dare great things and to carry them through. In a matter of weeks they were doing what was said to be safe only after years of experience-to drive dog-sledges, to hunt in the Eskimo method, to learn the kayak, to cross the ice-capped continent, to "live on the land'.

In a crowded year those fourteen men accomplished enough journeys, by air, by sledge, by kayak and motor boat, to be a credit to half a dozen expeditions. A splendid set of men, it is true, but they will all admit that their results were due to the qualities of their leader and to the utter confidence they had in him. Of some of them the world will hear in due course, for they have been trained by the amazing young man whose loss we now deplore.

Of slight build, though strong and supple, some- what shy and diffident in conversation, there was little in Watkins' appearance to mark him for what he was. Indeed, to the casual glance, his wellgroomed figure, his neatly parted hair, his charming but hesitant manner, were signs merely of a pleasant young man who would always follow the precept of others and live quietly but efficiently in some ordinary walk of life. A conversation with him began to awaken doubts as to his being merely that. The alert poise of his head, the quick seizure of essentials, the calm statements of daring plans, all betokened a man of ideas and with the will to carry them out.

Even so, it was not until one saw Watkins in action that one realised his full qualities. It matters not what the action might be, wrestling with a friend, scaling a mountain-side, or, better still, as can be seen in the film of his expedition, ' rolling' a kayak. At one moment he is at ease, smiling and joking, like any other debonair young man; at the next he is tense and alert, head thrust forward, jaws set, and eyes shining with an expression almost grim, balancing his craft for a moment. He flings himself backwards and there is a flurry of paddle and arms, a swirl and a splash, and there he is again, relaxed and at ease, with a shy smile as though he were rather ashamed of his relapse into intense activity.

There must be added to this picture a shy dignity and a charm of manner, a modesty and a thoughtfulness which won all hearts. That is why Dr. H. R. Mill, in his appreciation in the Times, used the apt phrase," so dear a scientific adventurer as "Gino "Watkins " ; that is why his companions would do anything for their leader, and why the news from Greenland has come as the shock of a bullet to his friends.

\section{News and Views}

\section{Function of the British Association}

IN suggesting as one reason for the continued success of the British Association the opportunity it affords, in an age of specialisation, for laymen to have intelligent contact with the seekings and findings of the scientific mind and for science to expound its own broad outlook, Sir Alfred Ewing, whose presidential address is printed in our Supplement this week, is on firm ground. The passing of the arroganee characteristic of an earlier age, the widespread belief that there are in science no longer any rigorous laws but only laws of probability, have made for a spirit which strengthens the sense of brotherhood between the scientific expert and the average man, who in his own way is also commonly a seeker after truth. The disappearance of dogma alone should assist the formation of an alliance which is overdue if we are to carry over into human affairs the methods of science and apply the dispassionate temper of science to the solution of our social, economic, and international difficulties.

\section{Progress in Engineering Science}

AFTER an engineer's review of the rapid progress in the study of the atom during the last few decades, including the discoveries of the neutron and the splitting of the lithium atom described this year, Sir Alfred Ewing referred to the important contribution of the Association to the advancement of engineering science. Early reports submitted to the Association demonstrated the conspicuous lack of science on the part of early British engineers, and the meagre contributions being made by them to the progress of hydraulies in contrast with the contributions of Italy, France, and Germany. The claim that the British Association by its reports and investigations, its discussions and committees, such as those leading to the establishment of the National Physical Laboratory and international standards for electrical units, has provided an invaluable scientific leaven, few would care to dispute. In his own recollections Sir Alfred Ewing covers the passing of many of the former fairy tales of science into the tissue of everyday life, and in the transition British engineering science has made as important scientific as practical contributions.

\section{The Future of Science}

A conspicuous feature in any such review is bound to be the realisation of the accelerated pace at which 